\title{
A obra completa de Max Weber - MwG \\ Um retrato
}

Edith Hanke

Tradução de Sibele Paulino

A edição crítica Obra completa de Max Weber (MWG - Max Weber Gesamtausgabe) abarca atualmente (fevereiro de 2012) 33 volumes, dos quais $22 \mathrm{da}$ seção I, "Escritos e discursos"; 6 da seção II, "Cartas"; 5 da seção III, "Cursos e anotações de cursos". Planejada para encerrar em 2015, essa edição em língua alemã contará com 47 volumes e irá apresentar, com comentários críticos e históricos, a obra completa de Max Weber que chegou até nós. Embora ainda faltem volumes importantes, como a edição de $A$ ética protestante e os escritos metodológicos, a MWG há anos já é considerada uma das maiores e mais criteriosas edições em língua alemã de clássicos nas áreas de ciências sociais e ciências da cultura. Um volume com seiscentas páginas impressas custa, em média, cerca de $€ 240,00$ (aproximadamente $\mathrm{R} \$ 560,00$ ) e tem um período de elaboração de cinco a oito anos. Quem possui hoje todos os volumes tem um valor material acumulado de aproximadamente $€ 8$ 800,00 $(\mathrm{R} \$ 20700,00)$ e aprecia o produto de uma atividade equivalente a 230 anos de trabalho científico. O preço e a aparência externa da MWG indicam o padrão de qualidade a que a edição se propõe. Ao lado de compradores particulares de todo o mundo, a MWG é adquirida sobretudo por bibliotecas e institutos. Ela pode ser consultada nas bibliotecas de universidades alemãs e também na Columbia University, em Nova York, na Universidade de Osaka, ou na Universidade de São Paulo. Até o colapso do iene, a maior parte dos exemplares eram vendidos a pesquisadores de Weber no Japão. 
Ela é dirigida a um público de especialistas da Alemanha e do exterior que se interessa tanto por um texto filologicamente confiável, com contextualização e comentário adequados, como pelas manifestações de Max Weber em suas cartas. A editora também oferece por um preço mais acessível uma "edição de estudo" dos volumes da seção I da MWG, sem a indicação das interferências textuais e sem as notas explicativas.

Na sequência, a MWG será retratada brevemente em quatro partes: características gerais de sua organização e de sua origem, fundamentos editoriais e atividade de compilação acessória à ediçãa. Um breve excurso questiona-se sobre o "valor" da MWG.

0 "empreendimento" MWG

As duas folhas de rosto de cada volume dão notícia sucinta e incisiva sobre as características gerais da organização da MWG. Embora ao se abrir o volume o olhar se volte automaticamente para a página direita, nesse caso é a esquerda a mais decisiva para o reconhecimento da estrutura básica da edição, pois ali são elencados seus principais responsáveis: a MWG, "por encargo da Comissão de História Social e Econômica da Academia de Ciências da Baviera", é editada pelos seguintes profissionais, mencionados nominalmente: Horst Baier, Gangolf Hübinger, M. Rainer Lepsius, Wolfgang J. Mommsen, Wolfgang Schluchter e Johannes Winckelmann. Aqueles já falecidos, Winckelmann e Mommsen, são assinalados com uma cruz, mas continuam sendo apresentados e reconhecidos pelos serviços prestados à edição. Por fim, ao pé da página, é indicada a editora J. C. B Mohr (Paul Siebeck), da cidade de Tübigen, com seu emblema. Por intermédio da Comissão de História Social e Econômica, a MWG está vinculada à Academia de Ciências da Baviera. No início do empreendimento, o grupo de editores decidiu por esse enquadramento institucional. A Academia administra a maior parte dos recursos financeiros e é, ao mesmo tempo, a empregadora da maioria dos colaboradores científicos da MWG (no momento, nove). A plena responsabilidade científica e organizadora cabe aos editores nominalmente mencionados. Estes são cientistas de diferentes áreas que tomaram a tarefa para si e comprometeram-se, por meio de um contrato, com a Academia e a editora. Os editores encontram-se regularmente nas chamadas reuniōes editoriais, que servem para consultas e tomadas de decisões por consenso. Essas reuniões são registradas em atas e têm caráter deliberativo. Desde a reunião inaugural, em dezembro de 1975, M. Rainer Lepsius desempenha 
o papel de editor-gestor da MWG. A editora Mohr-Siebeck é o terceiro pilar da organização, tendo o direito exclusivo de impressão e distribuição da MWG, que ela financia com seus próprios recursos.

$\mathrm{Na}$ organização da MWG há, portanto, uma mescla de diferentes características estruturais: a Academia enquanto instituição estatal que se encarrega das tarefas administrativas; em seguida, a agremiação de cientistas voluntários, dotados de competência especializada e, finalmente, a editora, que assume os riscos e a responsabilidade econômica. Cada um dos três tem competências e tarefas distintas, mas estão ligados por meio de um contrato e são mutuamente comprometidos. Na realidade, trata-se de um modelo civil de cooperação assumida voluntariamente, que se tem conservado há mais de 35 anos.

De volta à folha de rosto. Na página à direita, sob o título do volume, são nomeados o(s) editor(es) e, conforme o caso, seus colaboradores. No volume III/6, que acaba de ser publicado, o editor é Wolfgang Schluchter, com a colaboração de Joachim Schröder. O editor de cada volume é responsável pelo conteúdo editado dos textos ou das cartas de Weber. Ele escreve a introdução, cujo intuito é indicar o horizonte biográfico e histórico-científico da obra e que deve contribuir para a compreensão dos textos editados. A revisão dos textos, o estabelecimento do aparato editorial, as notas explicativas, a composição dos relatórios ou notas preliminares editoriais, assim como dos índices, são, por outro lado, tarefa dos colaboradores científicos, que trabalham sob a coordenação e a supervisão especializadas do editor do volume. A comissão editorial encarrega um editor para organizar determinado volume. No exemplo mencionado, Wolfgang Schluchter é, ao mesmo tempo, editor e membro da comissão. Para a escolha, é decisiva a competência especializada; por exemplo, os volumes de história social e econômica antiga foram editados pelo historiador da Antiguidade Jürgen Deininger; o de sociologia da música, pelos musicólogos Christoph Braun e Ludwig Finscher; o volume sobre confucionismo, pelo sinólogo Helwig Schmidt-Glintzer e o volume sobre judaísmo antigo, pelo especialista em Antigo Testamento Eckart Otto. Os volumes de cartas foram editados por Rainer Lepsius e Wolfgang J. Mommsen e, depois da morte deste último, por Gerd Krumeich. Lepsius ficou responsável pelas cartas de conteúdo privado; Mommsen e Krumeich, pelas de conteúdo político e científico.

Quando se vira a folha de rosto, é possível localizar os nomes dos redatores científicos responsáveis e, sobretudo, algo sobre o financiamento dos traba- 
lhos de edição. Enquanto os editores trabalham de modo voluntário, os redatores e colaboradores científicos são profissionais contratados. Além disso, são financiados materiais de apoio, gabinetes, assistentes e viagens a arquivos. Via de regra, os editores confiaram aos colaboradores de suas respectivas cátedras os trabalhos da edição e também ficaram encarregados do seu financiamento. Durante muitos anos, a Sociedade Alemã para Pesquisa (DFG) sustentou os postos de colaboradores e as expensas materiais. Desde 1996-1997, uma parte considerável do financiamento da MWG foi assumida pelo assim chamado "Programa das Academias", que teve suporte do Ministério Federal de Educação e Pesquisa (BMBF) e dos respectivos estados federados. Nesse programa, foi incluída a edição de Economia e sociedade, das cartas e dos cursos, bem como dos trabalhos de redação. Esse financiamento terminará em dezembro de 2015. Além disso, volumes ainda inconclusos terão que ser financiados por outras fontes. Atualmente, é este o caso dos trabalhos dos dois volumes de $A$ ética protestante, dos escritos metodológicos e dos textos sobre política universitária. Nesses casos, os próprios editores de cada volume captaram recursos de instituições de fomento e de terceiros para a remuneração de seus colaboradores.

O velho princípio de que o trabalho de edição deve ser executado no lugar em que se encontra o pessoal qualificado levou a MWG a uma estrutura organizacional descentralizada. Nos lugares onde se desempenhavam as atividades de edição foram instalados grupos de trabalho, que hoje se encontram nas seguintes instituições: universidades de Düsseldorf, Frankfurt-am-Oder, Frankfurt-am-Main, Heidelberg, Kassel e Academia de Ciências da Baviera, em Munique. O grupo de Munique é, ao mesmo tempo, a sede da redaçãogeral e o escritório da MWG. Nos espaços da Academia está localizada também a Biblioteca de Johannes Winckelmann, com acervos de compilações e pesquisa, de que se falará mais adiante.

Antes que se possa ter em mãos um volume impresso da MWG, ele teve uma longa história atrás de si e passou por diferentes instâncias de controle. $\mathrm{O}$ trabalho de edição propriamente dito ocorreu em diferentes locais, na interação do editor de cada volume com seus respectivos colaboradores e sob o amparo da redação, que tem função de assessoramento e apoio. Tão logo o texto esteja fixado, ele é primeiramente conferido e examinado pela redação quanto à observância das regras editoriais e então entregue à comissão de editores para a emissão de um parecer. A cada vez se define um relator do grupo de editores, que apresenta um parecer interno sobre o material apresentado. Em casos excepcionais, pode-se também solicitar um parecer externo. Como 
regra, as introduções de cada volume são lidas por todos os quatro editores. Após uma consulta detalhada, é tomada uma decisão definitiva e, em determinadas situações, requerem-se melhorias. A autorização formal para impressão é emitida pelo editor-gestor e endereçada à Comissão de História Social e Econômica. Então, começa de fato a preparação para a impressão, e a redação assume o contato com a editora. Apesar dos meios de apoio técnicos e eletrônicos, muitos trabalhos ainda são feitos à mão, como a correção das provas impressas e a organização dos índices remissivos. Geralmente, são necessárias de duas a três etapas de correção para cada volume, de modo que o trabalho de preparação para a impressão dura aproximadamente um ano, a depender do tamanho do volume e da qualidade dos originais.

A experiência demonstrou que as diferentes instâncias de controle - a comissão de editores, no que concerne ao conteúdo; a redação, no que concerne às condições técnicas, assim como a produção artesanal cuidadosa por parte da editora - garantiram a elevada qualidade da MWG.

\section{Origens da edição}

Por que, afinal de contas, conceber uma nova edição crítica e histórica com tantos volumes? Depois da Segunda Guerra Mundial, ainda estavam disponíveis os livros editados por Marianne Weber; a eles se adicionaram, sob os cuidados de Johannes Winckelmann, as novas edições de Economia e sociedade, de Escritos políticos reunidos, de Escritos reunidos de teoria da ciência, de História econômica, assim como a edição de $A$ ética protestante e de Anticríticas. Além disso, havia os excertos de textos editados pelo Conde Max zu Solms e seu sobrinho, Conde Ernst zu Solms, e que foram publicados em 1947 e 1948, em Frankfurt-am-Main. Winckelmann lançou um novo reader com uma introdução do sobrinho de Weber, Eduard Baumgarten, pela editora Kröner. À exceção de Cartas de juventude, que Marianne Weber havia publicado em 1936, não havia ainda uma edição das cartas do autor. Seu conhecimento estava limitado aos fragmentos contidos na biografia de Max Weber escrita por Marianne, assim como ao material coligido no volume organizado por Eduard Baumgarten, Max Weber: obra e pessoa. Os cursos eram totalmente desconhecidos, exceto "História econômica", coligido por Siegmund Hellmann e Melchior Palyi em 1923, e revisto em 1958, por Winckelmann.

Esse estado de coisas foi motivo para que o médico e sociólogo Horst Baier (nascido em 1933) se mobilizasse, desde 1972, em intensas conversas preliminares e planejamentos voltados à organização de uma edição 
histórico-crítica da obra completa de Max Weber (cf. Hanke, Hübinger e Schwentker, 2010, pp. 207-237). Baier obtivera em Münster sua livre-docência com um trabalho sobre a metodologia de Max Weber, sob orientação de Helmut Schelsky, e desde 1970 lecionava sociologia na Universidade de Frankfurt-am-Main, como sucessor de Adorno. Vindo da Münster conservadora, ele passou para o coração da Teoria Crítica. Ao final da década de 1960 e inícios dos anos de 1970, Max Weber era considerado uma figura marginal e ultrapassada por pensadores convervadores como Hans Maier e Wilhelm Hennis. Ele era criticado por seu postulado da "neutralidade de valor". No ambiente de esquerda, ocorreu um debate mais intenso sobre Weber, visando uma rejeição radical de suas posições, tal como realizado inicialmente por Herbert Marcuse e por Jürgen Habermas (em seus inícios), e que teve um impacto público. O assim chamado "Debate Max Weber" foi conduzido de maneira polarizada. No debate científico da Alemanha Ocidental, o interesse pelo autor como fundador de uma ciência social empírica e valorativamente neutra estava a contrapelo do ambiente intelectual dominante. A percepção de crise da sociedade de bem-estar social, ao fim da revolta de 1968, coincidia com uma crise nas ciências sociais e humanas. Do lado conservador, foi declarada uma "mudança de direção" na qual Weber, no entanto, não desempenhava nenhum papel decisivo. A iniciativa de Horst Baier, portanto, deve ser vista como reação à percepção de uma crise. Com uma nova edição das obras completas de Weber, a posição de uma ciência social empírica e livre de valorações deveria ser reforçada.

$\mathrm{O}$ modo como Weber compreendia a ciência constituiu o denominador comum para o grupo de fundadores da MWG. M. Rainer Lepsius, naquela época professor de sociologia em Mannheim e presidente da Associação Alemã de Sociologia, ainda hoje relembra a luta contra a filosofia da história e a antropologia social, do ponto de vista da política científica, como o motivo decisivo para sua participação na MWG. Em uma de suas primeiras publicações, Wolfgang Schluchter - que obteve sua livre-docência em 1972 em Mannheim e tornou-se desde 1973 professor de ciências sociais em Düsseldorf - fundamentou a virada em direção a Max Weber com o argumento, em oposição às interpretações neomarxistas, de que somente com ele seria possível uma análise das sociedades industriais avançadas. Wolfgang J. Mommsen, professor de história moderna e contemporânea em Düsserldorf, conquistou notoriedade para além dos limites de sua disciplina com uma tese de doutorado sobre Max Weber e a política alemã ${ }^{1}$. Como único historiador da comissão, ele consultara originais de Weber em Merseburg (República 
Democrática Alemã) que eram desconhecidos de muitos especialistas em Weber na Alemanha Ocidental (sobretudo Johannes Winckelmann). Mommsen pertencia ao grupo de estudos "Teoria da História", que ligava um novo direcionamento teórico da história à metodologia de Max Weber. Embora não fosse um historiador social, Mommsen pode ser visto como mediador entre discursos sociológicos e de teoria da história. A MWG foi um projeto desses cientistas da "Geração de 45 "2 que, a partir da experiência do Nacional-Socialismo, pugnavam por uma democracia parlamentar. Isolados, eles se distinguiram como personalidades vigorosas na cultura científica da Alemanha Ocidental. Um pouco à margem desse grupo, mas desfrutando autoridade, estava Johannes Winckelmann que, sendo renomado editor e coligidor de textos de Weber, foi integrado ao projeto.

Horst Baier obteve apoio da Fundação Werner Reimer, de Bad Homburg, para as conversaçôes preliminares da MWG. No quarto encontro, em 4 e 5 de dezembro de 1975, constituiu-se a comissão de editores, com cinco integrantes, que estabeleceu uma espécie de estatuto com os princípios para a organização e um esboço da obra completa; isso com a presença dos editores Hans-Georg e Georg Siebeck. O secretário da cultura da Baviera, Hans Maier, também se interessou em fomentar o projeto. Depois de muitas negociaçôes entre a Academia de Ciências da Baviera, a Universidade de Munique e a Secretaria de Cultura, ficou determinado no final de 1975 que fossem destinados à Academia os meios financeiros necessários para a criação de um escritório para a edição da MWG.

A iniciativa da edição da MWG foi vista com frequência como um empreendimento politicamente motivado, paralelo à edição de Obra completa de Marx e Engels [Marx/Engels Gesamtausgabe-MEGA], em Berlim Oriental. Essa não era a intenção dos fundadores da MWG, que não pretendiam concorrer com a MEGA, mas sim marcar uma posição no debate científico na Alemanha Ocidental, na medida em que tomavam conscientemente partido por uma metodologia empírica e não valorativa na sociologia e na história. Foi esse o interesse político-científico original, que só pôde ser colocado em prática, no entanto, com apoio político - este sim ligado às invectivas antimarxistas mais aguçadas. A estrutura da MWG, descentralizada e ajustada às personalidades individuais dos editores, era de fato o contraponto burguês, liberal e individualista à MEGA, organizada de modo centralizador. Com o aparecimento dos primeiros volumes, em 1984, a MWG fomentou o interesse público por Max Weber, sendo este um fator importante para o renascimento do autor na Alemanha Ocidental.
2. O conceito foi introduzido por Moses (2007), para designar os intelectuais nascidos de 1922 a 1932. Cf. Cornelissen (2010, pp. 13 ss.). 


\section{Os princípios editoriais}

Por mais de seis anos os editores debateram sobre a definição de um perfil à MWG e de seus princípios editoriais. Como resultado, eles trouxeram a público, em 1981, o assim chamado "Prospecto verde", que divulgava a MWG. Ele continha a estrutura da edição (na época 33 volumes planejados), a "Introdução à Obra Completa de Max Weber", redigida por Wolfgang Schluchter, a bibliografia estabelecida por Martin Riesebrot e, como um modelo da edição, o discurso de Weber "A Alemanha dentre as potências mundiais europeias". Em 44 páginas encontram-se os fundamentos do trabalho editorial válidos até hoje, em especial, a "Introdução" de Wolfgang Schluchter, que pode ser lida como a "lei editorial básica" da MWG. Na elaboração desses princípios, os editores não seguiram a MEGA, mas se orientaram pela teoria da edição discutida sobretudo pelos germanistas no âmbito do Deutsches Literaturarchiv [Arquivo Literário Alemão], em Marbach. Em síntese, a MWG caracteriza-se como "uma obra completa documentada a partir de princípios histórico-críticos”.

O que isso significa? "Obra completa" significa que se leva em consideração todo o legado de Max Weber como autor, ou seja, todos os documentos escritos que lhe podem ser atribuídos com segurança. Entre estes, estão os textos publicados sob sua autoria, mas também os manuscritos que legou, inclusive as cartas publicadas anonimamente ou as transcriçōes de fragmentos de cartas. Na seção I de MWG, "Escritos e Discursos", o espectro varia de textos que o próprio Max Weber enviou para impressão - seja o célebre $A$ ética protestante, seja uma pequena resenha sobre a dívida pública do Egito, de 1893 - até os manuscritos não publicados por ele - como o adendo à crítica de Stammler, a sociologia da música ou a versão de Economia e sociedade anterior à Primeira Guerra Mundial. Ao lado disso, os discursos de Max Weber têm um papel importante - basta pensar em seu discurso inaugural na Universidade de Freiburg, de maio de 1895 ou nos discursos de Munique, "Ciência como profissão" e "Política como profissão", bastante citados; mas também nos discursos políticos, que ele proferiu em assembleias de massa ou nas conferências para especialistas em círculos restritos, como o Círculo Eranos, de Heidelberg. A isso se acrescentam as várias declaraçōes documentadas por ocasião de congressos, como nas assembleias gerais e reuniōes de comitês da Verein für Sozialpolitik [Associação para a Política Social], do Evangelisch-sozialer Kongress [Congresso Social Evangélico - ESK], da Deutsche Gesellschaft für Soziologie [Sociedade Alemã de Sociologia] 
ou nas jornadas de Docentes do Ensino Superior. Uma fonte importante para isso são as atas com as comunicaçôes autorizadas dos participantes. Onde faltam as atas, entram como comprovações substitutas as notícias de jornal, anotações feitas na época por terceiros, ou algo semelhante. Além disso, há as conclamações coassinadas por Weber, que lançam luz sobre seu engajamento político e social. Mais recentemente, por exemplo, foi descoberta uma, assinada com Thomas Mann em março de 1920, em prol dos escritores necessitados. Como resultado dos trabalhos editoriais para o volume I/13, "Ensino superior e política científica", os apontamentos de Max Weber sobre as circulares da faculdade ganham novo significado. Aqui é possível conhecê-lo como professor universitário e como um colega nem sempre muito fácil. Todos esses textos e fragmentos foram levantados pela primeira vez na bibliografia de Martin Riesebrodt. Uma bibliogafia expandida do outono de 2002 abrange quase quatrocentos títulos ${ }^{3}$ e pode ser complementada até hoje a partir de novas indicaçôes.

Além disso, também cartas, cartões postais, telegramas e outros documentos epistolares integram o legado do autor, e são editados na seção II de MWG. Aqui exigiu-se dos editores um enorme trabalho de busca, dado não existir propriamente um espólio de Max Weber. Para reunir as correspondências foi preciso recorrer a diferentes espólios parciais e legados privados. Sobre isso se falará adiante, na seção deste artigo sobre a atividade de coleta. No momento, a MWG registrou quase 3,5 mil cartas em um banco de dados para uso interno. No prelo, estão as de 1918 a 1920, que abrangem os últimos anos de vida de Weber e revelam uma conexão surpreendente entre reviravoltas políticas, científicas e pessoais. Ele comentou o fim da Primeira Guerra Mundial com uma sobriedade perspicaz, engajou-se em favor da reformulação da constituição alemã e fez discursos políticos. Marianne Weber teria gostado de vê-lo presidente do Reich, mas o próprio Weber reconhecia ser, sobretrudo, um erudito. Como consequência dos prejuízos financeiros decorrentes dessa guerra, Weber precisou considerar o retorno às atividades de magistério regular. Lecionou inicialmente em Viena, a título de experiência, e então em Munique, a partir do verão de 1919. Ali ele se empenhou na fundamentação da sociologia como disciplina universitária e na impressão de seus Escritos reunidos de sociologia da religião e de Economia e sociedade. Também a sua vida pessoal sofreu uma reviravolta; ele se mudou de Heidelberg para Munique para poder viver próximo de sua ex-aluna Else Jaffé. Além de declarações científicas e relativas à alta política, o volume também recolhe cartas muito íntimas, propiciando um retrato bastante
3. Essa bibliografia está disponível na página eletrônica da editora Mohr. 
denso da personalidade de Weber e de sua situação de vida. As introduções e comentários especializados, que aclaram a obra epistolar, são especialmente valiosos; em 1991, os editores foram agraciados com o Prêmio Amalfi pelo volume de Cartas II/5.

As mais de 1,5 mil páginas de apontamentos manuscritos de Max Weber, que serviram de base para seus cursos ministrados entre 1894 e 1899, quase não são conhecidas na comunidade científica weberiana. Elas oferecem uma visão do cânone doutrinário na área de economia política da época e, ao mesmo tempo, fazem conhecer o próprio posicionamento metodológico de Weber, sobretudo sua forma de abordagem sob o viés da história econômica. Ademais, elas comprovam seu conhecimento abrangente da literatura e das fontes, que se depositou mais tarde em Economia e sociedade. Com a ajuda dos catálogos de disciplinas e, em parte, dos livros de matrícula das Universidades de Berlim, Freiburg, Heidelberg, Viena e Munique, pôde-se reconstituir quais cursos Max Weber anunciou e quais de fato ministrou. Sobre alguns, infelizmente não há comprovações diretas ou indiretas, como o ministrado em Viena, como professor visitante, em 1918. Por outro lado, a estrutura e o conteúdo de dois deles ministrados em Munique foram documentados por meio de anotações feitas por ouvintes, durante as aulas ou em momento posterior. Nesse caso, as anotações servem como substitutos para o História econômica e o Sociologia do Estado.

Na MWG, não são editados, via de regra: excertos, intervenções redacionais de Max Weber em textos de outras pessoas, marginálias em livros utilizados por ele. Dependendo da relevância do conteúdo pode haver, no entanto, informações nos relatos editoriais. Mas há também exceções; por exemplo, no volume de documentação I/24 sobre Economia e sociedade foram incluídos casos selecionados de suas intervenções redacionais no planejamento, nos contratos editoriais ou nas contribuiçóes apresentadas para o Grundriss der Sozialekonomik [Compêndio de economia social], para evidenciar a abrangência de sua atividade como editor. Do mesmo modo, será publicado no volume I/12 um excerto pormenorizado sobre o Sociologia, de Simmel, porque ele documenta com que intensidade Weber se confrontou com as proposições do segundo founding father da sociologia alemã. De modo geral, excluiu-se a correspondência passiva como não pertencente ao legado próprio do autor. Hoje se costuma lamentar essa decisão, que corresponde, no entanto, à concepção originalmente acordada pelos editores.

Antes da publicação do "Prospecto verde", os editores decidiram pela subdivisão da obra completa em três seções, sendo a categoria textual o cri- 
tério decisivo para a alocação na seção I ("Escritos e Discursos”), II (“Cartas”) ou III (“Cursos e anotaçōes de aulas”). No entanto, houve muito conflito, especialmente sobre os princípios de disposição dentro da seção I. Como os textos deveriam ser distribuídos pelos volumes? Decidiu-se por uma mescla de critérios de conteúdo (pertinência) e de sequência temporal (cronologia). Assim, escritos singulares que preenchem um volume, como a tese de doutorado, a tese de livre-docência ou a sociologia da música, não apresentaram dificuldades. Para os artigos, discursos e contribuições a discussões, porém, foi preciso criar unidades de volume com títulos inventados e abrangentes, como, por exemplo, o volume I/4 "Questão dos trabalhadores agrários, o Estado nacional e a política econômica. Escritos e discursos 1892-1899" ou, mais recentemente, o volume I/6 "Sobre a história social e econômica da Antiguidade. Escritos e discursos 1893-1908”“4. Em todos esses casos, os editores discutiram intensamente e pesaram todos os argumentos. Nessa ordenação aparece, talvez do modo mais evidente, a vontade da comissão de editores, no que diz respeito ao modo de dar forma à concepção e ao conteúdo; ela marca claramente a divergência em relação às edições anteriores. A mescla entre pertinência e cronologia também foi empregada na divisão dos volumes dos cursos ministrados, na seção III. Em virtude da situação do material disponível, as anotaçôes de cursos específicos foram ordenadas e, quando ministrados mais de uma vez e com títulos variados, providas de um título inventado, por exemplo, o volume III/5 "Direito agrário, história agrária, política agrária. Cursos 1894-1899”. Apenas a edição de cartas segue exclusivamente o princípio cronológico.

Uma edição documental distingue-se de uma interpretativa na medida em que evidencia as decisões editoriais, deixa clara a proveniência dos textos e informa sobre todas as intervenções realizadas nos textos. Ao contrário da tradição do século XIX, em que o editor acreditava conhecer exatamente a vontade do autor (como é claramente o caso de Vontade de poder, de Nietzsche, editado por sua irmã Elisabeth Förster), a MWG conclama não um editor invisível, mas em grande medida aquele que reflete sobre sua atuação editorial e a documenta. Na MWG, o lugar sistemático desse tipo de prestação de contas são os relatos editoriais ou as notas editoriais preliminares. Antes de cada unidade de edição, eles informam sobre a origem, a procedência e eventualmente sobre especificidades editoriais, caso estas não sejam abrangidas nos princípios impressos no final de cada volume.

A eficiência dos princípios de uma edição documental foi colocada à prova especialmente no trato com as partes póstumas de Economia e sociedade.
4. Cf. também o comentário de Mata (2011, pp. 175-178). [N. E.] 
5. Primeiramente em $M W G$ I/22-5, pp. vii-xvii, sob o título: "Zur Edition von, Wirtschaft und Gesellschaft. Allgemeine Hinweise der Herausgeber der Max Weber-Gesamtausgabe”.

6. A esse respeito, ver a contribuição mais pormenorizada de M. Rainer Lepsius neste Dossiê. [N. E.]
Os editores responsáveis consideraram este o verdadeiro desafio editorial e por isso redigiram, em 1999, uma nota em comum, que fundamenta seus procedimentos $^{5}$. O corpus textual era conhecido pelos vários especialistas em Weber, alemães ou estrangeiros, por meio da quarta e quinta edições de Johannes Winckelmann. Em comparação à primeira edição de Marianne Weber e Melchior Palyi, Winckelmann interveio muito fortemente nos textos, nos títulos e na estrutura. Isso é especialmente evidente na seção 8 da sociologia da dominação, por ele acrescentada: "A instituição racional do Estado e os parlamentos e partidos políticos modernos (Sociologia do Estado)" ". Ainda hoje, há especialistas que dão mais credibilidade a esse pecado editorial do que à nova edição da MWG, na qual falta esse capítulo estranho. A edição da versão mais antiga de Economia e sociedade, nos volumes parciais I/22-1 a 5, é um exemplo de como se teve que afastar a longa sombra editorial de Johannes Winckelmann. Como fundamentos textuais, os editores recorreram aos manuscritos originais de Sociologia do direito e da seção "A economia e as ordenações", assim como à tradição textual da primeira edição.

Método histórico-crítico significa que o material relevante para a edição é conferido e submetido a um estema, quando proveniente de fontes diversas. Edita-se o texto de "última mão" ou seja, o que foi entregue pelo autor para impressão, e não o de fases preliminares (manuscrito ou provas de impressão). "Histórico" significa que a gênese do texto é documentada e que divergências em relação à última versão deste ficam registradas em um aparato de variantes. Quando há proveniências diversas, é possível comparar as diferentes variantes do texto e, com isso, compreender sua gênese em cada uma das fases. Além disso, cada unidade de texto é conferida para controle de erros e deturpações. As variantes e correções do texto são dispostas no aparato crítico e indicadas nos trechos correspondentes por meio de letras em sobrescrito.

Entre as atividades de correção do texto está a padronização dos nomes próprios, como foi frequentemente o caso das anotações de aulas que chegaram até nós, em que os estudantes ou entendiam um nome de maneira evidentemente incorreta, ou o reproduziam com uma transcrição fônica aproximada, como "Reisicka" em vez de "Preisigke". Já os primeiros editores de Economia e sociedade se queixavam das várias palavras estranhas, que decerto não puderam conferir diretamente. Assim, nas antigas edições impressas dessa obra encontra-se a formulação sobre ordens nos “movimentos escatológicos (metodistas)" no Islā, embora o correto seja 
"movimentos madistas", como também comprova o fragmento do manuscrito ora encontrado.

Por que é necessária a comprovação das diferentes versões do texto? Isso é especialmente interessante no caso de $A$ ética protestante, cuja primeira versão foi publicada entre 1904-1905 no Archiv für Sozialwissenschaft und Sozialpolitik [Arquivo para a ciência social e a política social] e elaborada em uma versão ampliada por Weber em 1920, para o primeiro volume dos Escritos reunidos de sociologia da religião. Klaus Lichtblau e Johannes Weiss produziram uma edição em brochura da versão publicada entre os anos de 1904-1905 e listaram os acréscimos em um anexo, mas sem apontar aí todos os detalhes (Weber, 1993a, pp. 157-203). A MWG irá editar as duas versóes separadamente e indicar no aparato crítico da versão posterior as divergências em relação à edição mais antiga, de modo que se possa acompanhar a cada página exatamente o que Weber modificou. Adicionalmente serão incluídas as provas de impressão corrigidas pelo autor, pois com base nelas evidenciam-se de maneira muito plástica as etapas de desenvolvimento do texto e comprova-se a hipótese de Wolfgang Schluchter de que, em seu âmago, a tese da ética protestante não sofreu qualquer mudança; ocorreu, isso sim, que Weber guarneceu sua posição contra as objeções levantadas nas críticas e se confrontou principalmente com as teses de Sombart ${ }^{7}$. Do mesmo modo, o manuscrito utilizado no discurso "Política como profissão", quando comparado com o texto escrito, oferece um exemplo contundente do valor das variantes. Enquanto no manuscrito da conferência de 28 de janeiro de 1919 o autor ainda fala de "política da convicção e política da responsabilidade (pelo poder)”, na versão escrita de junho de 1919 trata-se explicitamente de "ética da convicção" e "ética da responsabilidade". Ou seja, a comparação das duas versões torna visível o "salto categorial" ocorrido.

Muitos usuários da MWG, no entanto, reconhecerão o valor da edição sobretudo na elucidação dos textos e das cartas por meio de comentários especializados, e em igual medida pelo acesso rápido proporcionado por índices remissivos de pessoas e temas. A função dos comentários especializados é o aclaramento (e eventualmente, a correção) de citações e referências, a identificação de pessoas e a explicação de referências especializadas. Quem tomar em mãos os primeiros volumes publicados da MWG (I/3 e I/15) constatará que especialmente o aparato explicativo se tornou mais extenso ao longo do tempo. Sem dúvida, a exigência com relação à contextualização histórico-científica dos textos e cartas aumentou, embora o ideal de um “comentário ascético" tenha permanecido.
7. A esse respeito, ver a "Introdução" de Wolfgang Schluchter (cf. MWG III/6, pp. 1-45, especialmente. pp. 44 ss). 
Apesar dos princípios editoriais, cada seção e cada volume tem sua própria feição. Trata-se a todo momento da adaptação de regras a um caso concreto. Isso exige discussões e processos de conciliação, eventualmente também ampliações e modificaçóes dos princípios e regras estabelecidos em 1981. No caso das seçôes II e III, as regras editoriais desenvolvidas para a seção I foram adaptadas às exigências da edição de cartas e cursos. Por fim, cada volume comporta um balanço por parte dos responsáveis, que unifica a reflexão crítica e a responsabilidade.

\section{Os acervos da coleção}

Da fase de planejamento até a publicação do primeiro volume da MWG, "Sobre a política durante a Guerra Mundial” (I/15), em 1984, transcorreram mais de dez anos. Esse tempo não serviu apenas ao desenvolvimento dos princípios editoriais, mas sobretudo à reunião de documentos de arquivo, à exploração sistemática de espólios, assim como à procura de manifestações de Weber ainda desconhecidas. Reunir e organizar são pressupostos indispensáveis para um trabalho editorial sólido. Em sua fase inicial, a MWG pôde se apoiar em diferentes coleções, mas também aprimorar continuamente o seu conhecimento por meio de pesquisas.

A Coleção Winckelmann originou-se depois da Segunda Guerra Mundial. Johannes Winckelmann, jurista de formação, não conheceu Max Weber pessoalmente, mas já o admirava em sua época de estudante nos anos de 1920. Winckelmann renunciou à carreira de jurista na administração pública e, depois, à de consultor jurídico do Banco Central do Estado de Hessen, em 1951, para poder dedicar-se integralmente à obra de Max Weber como intelectual independente. Ao lado da edição dos escritos de Weber, ele prestou um grande serviço ao criar um Arquivo Max Weber, em Munique. Manteve uma correspondência intensa e longa com os contemporâneos ainda vivos de Weber e solicitou-lhes memórias, originais, exemplares de uso particular, anotações feitas durante suas aulas ou depois delas - simplesmente tudo que tivesse relação com o autor em questão. Por meio dos contatos, Winckelmann recebeu várias indicações de onde ainda poderia encontrar algo. Por exemplo, o professor Heinz Maus, de Marburg, informou-lhe em caráter confidencial que no gabinete do Conde Max zu Solm havia manuscritos de Weber emoldurados. Na metade dos anos de 1990, isso se revelou com o manuscrito de base do capítulo "Estado e hierocracia", de Economia e sociedade. Mas foi com Karl Loewenstein que Winckelmann conseguiu seu melhor lance. Loewens- 
tein legou-lhe como doação, em 1961, o manuscrito original de Sociologia do direito e a curta seção "A economia e as ordenações", sob a condição de que fossem depositados em um arquivo adequado. Essa foi a pedra fundamental para o Arquivo Max Weber, de Winckelmann. A ele se acrescentaram o manuscrito do discurso "Política como profissão" e outros manuscritos de aulas, correções de provas, excertos sobre Simmel e as anotações de aula feitas por Else Jaffé (como estudante: Else von Richthofen), Hans Ficker, Georg Girisch e Erwin Stölzl; além disso, algumas cartas originais de Max Weber, sua máscara mortuária, bem como o busto de bronze feito por Arnold Rickert, filho do filósofo Heinrich Rickert. O Arquivo Weber foi alojado inicialmente no Instituto de Sociologia da Universidade Ludwig Maximilian de Munique, Theresienstrasse n. 5, depois Konradstrasse, n. 6, onde também ficava o gabinete de Winckelmann, que era professor honorário. Quando ele decidiu se aposentar no começo dos anos de 1970, ocorreram conflitos com o Instituto de Sociologia por causa do acervo da coleção e da biblioteca de pesquisa sobre Weber que ele havia montado. Ao fim de 1975, o Ministério da Cultura da Baviera ordenou a transferência do acervo para a Academia de Ciências daquele estado. Os originais permaneceram lá, porém foram depositados em 1982 na Biblioteca Estatal da Baviera, já que ela garantia condições de conservação profissional.

O espólio familiar. Os documentos que se encontravam em poder da família tiveram grande importância, especialmente para a edição das cartas. Trata-se do espólio direto de Marianne Weber que, após ter falecido em 1954, foi dividido entre os filhos adotivos Weber-Schäfer e o sobrinho Eduard Baumgarten. A maior parte desse espólio encontrava-se em Konstanz com Max Weber-Schäfer, que era ao mesmo tempo representante dos herdeiros. Fazia parte do espólio: as cartas de Max a Marianne Weber; correspondências do autor, preservadas parcialmente, com parentes ou outras pessoas, assim como uma parte das correspondências com a família (ativa e passiva), e até mesmo as cartas de condolências por ocasião de sua morte; além de manuscritos isolados. Não se trata de um espólio completo, mas sim parcial e lacunar. O editor Georg Siebeck incitou a família WeberSchäfer a deixar os seus documentos herdados à disposição da edição e a depositá-los na Biblioteca Estatal da Baviera. Isso ocorreu em março de 1988, sob a intermediação de Horst Baier, que tinha proximidade com a família Weber-Schäfer em Konstanz. Junto com Max Weber-Schäfer, ele trouxe os espólios de Max e Marianne Weber para Munique. Para facilitar juridicamente a ação da família Weber-Schäfer, o editor antecipou-se e 
deu o bom exemplo, depositando já no início de 1980 a correspondência da editora com Max e Marianne Weber, entre 1895 e 1924, na Biblioteca Estatal em Munique. Ele negociou com a Biblioteca o primeiro termo de depósito, que serviu de modelo para os posteriores.

O sobrinho de Weber, Eduard Baumgarten, recebeu como herança apenas alguns documentos isolados. Quando estudante, ele tinha assistido aos cursos de Weber em Munique e esteve em seu leito de morte. Até a idade avançada, ele sentiu-se ligado ao tio e desenvolveu intensamente a atividade de compilação, que tomou forma em seus projetos de publicação. Em 1964, por ocasião dos 100 anos de nascimento de Max Weber, publicou sua monografia Max Weber: obra e pessoa. Depois, iniciou um livro que deveria conter as cartas do tio à esposa e às duas amantes, Mina Tobler e Else Jaffé-Richthofen, mas que não foi concluído. Em seu assim chamado Arquivo de Ebnet, pequena localidade próxima a Freiburg, Eduard Baumgarten havia disposto cuidadosamente todos os documentos originais e os ordenado com siglas próprias. No verão de 1970, ele transferiu parte do seu arquivo à coleção de Winckelmann; as cartas, no entanto, permaneceram inicialmente em poder da família. Somente anos depois, em 1982, a família Baumgarten-Schoeppe fez um acordo com a Biblioteca Estatal e lá depositou a maior parte das cartas de Max Weber.

O espólio de Max Weber da Biblioteca Estatal da Baviera foi organizado sob a rubrica "Ana 446", e hoje consiste em quatro acervos depositados e em um acervo próprio da biblioteca, que contêm os documentos por ela adquiridos. Os proprietários prontificaram-se a entregar sua Weberiana a um arquivo público, para que servisse de subsídio primário à edição. Por isso, o acesso em Munique não é livre, mas dependente do consentimento dos depositários e do editor-gestor da MWG. O espólio de Max Weber em Munique foi especialmente enriquecido devido à intensa atividade compiladora de Guenther Roth que, com vistas à biografia da família Weber, que ele publicou em 2001, havia reunido mais de mil cartas das famílias Fallenstein-Souchay-Baumgarten. Ainda há partes do espólio familiar que permanecem em posse de particulares, exceto no caso de haverem sido entregues ao Instituto Marianne Weber, em Oerlinghausen. Os poucos exemplares de livros que pertenceram a Max Weber também provêm da família e estão no escritório Max Weber da Academia de Ciências da Baviera em virtude de doação ou aquisição (164 exemplares no total).

O espólio científico. Segundo o relato dramático de Johannes Winckelmann, em meio à Segunda Guerra Mundial dois senhores de Berlim 
exigiram da viúva de Weber, na época com mais de 70 anos, que desse o espólio científico de seu marido para o Arquivo Estatal [Staatsarchiv] de Berlim, para que fosse preservado de maneira segura como bem de "importância nacional". Como se pode depreender das atas do Arquivo Secreto Estatal [Geheimes Staatsarchiv] do Patrimônio Cultural Prussiano [Preussischer Kulturbesitz], o pacote, vindo de Heidelberg, foi registrado em 30 de junho de $1943 \mathrm{em}$ Berlim. Por causa das ameaças de ataques aéreos, os acervos do Arquivo Estatal foram depositados em galerias subterrâneas de minas desativadas e o acervo de Weber foi levado a Stassfurt, no estado de Sachsen-Anhalt. Depois da Segunda Guerra Mundial, portanto, o espólio encontrava-se na Alemanha Oriental e foi depositado no Arquivo Central do Estado [Zentrales Staatsarchiv] da República Democrática Alemã, sucursal Merseburg. Um primeiro inventário foi realizado em 1966, quando as atas também foram encadernadas em brochura. $\mathrm{O}$ cientista político dinamarquês Hans Henrik Bruun enviou a Johannes Winckelmann, por carta, um relato sobre o acervo. Revelou-se então que o espólio continha sobretudo as anotações de Max Weber para seus cursos, assim como apontamentos científicos e excertos, mas também um acervo considerável de cartas e transcriçôes de cartas, que haviam servido a Marianne Weber para a composição da biografia do autor. Instigado por ela, Johannes Winckelmann, no início dos anos de 1950, dirigiu-se a Theodor Heuss, então presidente da República e que havia sido um conhecido pessoal de Max Weber, e pediu-lhe para tomar providências, por vias superiores, quanto ao paradeiro da Weberiana. Somente depois da reunificação da Alemanha é que esse acervo do espólio foi levado de volta de Merseburg a Berlim. Ao lado do acervo de Munique, trata-se do segundo maior espólio parcial de Max Weber (sob a sigla GStAPK, VI. HA, Nl. Max Weber).

A complementação científica e a compilação desse material ocorreu nos grupos de trabalho. Em Düsseldorf, sob a direção de Wolfgang J. Mommsen, catalografaram-se e transcreveram-se especialmente as cartas científicas e políticas. Em busca de outras correspondências, arquivos nacionais e universitários foram vasculhados sistematicamente, além das consultas a acervos particulares. Esse trabalho de base foi realizado principalmente por Manfred Schön que, em pesquisas a arquivos, prestou contribuição essencial para a elucidação da história científica do período de 1900. Além disso, realizou-se uma busca sistemática por artigos, conclamaçôes, cartas de leitores e relatos sobre as declaraçôes públicas de Max Weber em bibliografias, revistas e 
jornais. Com isso, o grupo de trabalho de Düsseldorf pôde acrescentar, já nos primeiros anos, mais de sessenta títulos à bibliografia de Weber. Esta foi compilada sistematicamente por Martin Riesebrodt, o primeiro colaborador científico do grupo de trabalho de Munique. Em Mannheim (e, posteriormente, em Heidelberg) foram reunidas e transcritas as cartas privadas de Max Weber, especialmente por Diemut Moosmann. O grupo de trabalho de Munique abarca os acervos da coleção e da biblioteca de Johannes Winckelmann que foram continuados e ampliados, seguindo a sistemática deste. Ao lado dos exemplares do próprio Max Weber, o escritório reúne ainda uma reconstituição da biblioteca do autor. Além de textos da autoria dele, colecionam-se também materiais sobre sua obra e sua biografia. $\mathrm{O}$ acervo da literatura de pesquisa e de traduçóes de Max Weber é extraordinário, o que contribui para que o grupo de trabalho receba amiúde a visita de especialistas estrangeiros. $\mathrm{O}$ grupo de trabalho de Munique assumiu a função de centro de compilação e informação para a MWG.

O "valor" da obra completa: um exame final provisório

"Muito cara", "dispendiosa", "sociologicamente unilateral" - essas foram as acusações que Wilhelm Hennis havia levantado contra a MWG no jornal Frankfurter Allgemeine Zeitung, em 1984 (cf. Hennis, 1984, p. 10; 2003, pp. 73-86). Durante muitos anos, ele foi considerado o crítico mais contundente da MWG, mas, depois, assim como Saulo tornou-se Paulo, ele exprimiu apaixonadamente seu tributo à MWG: "Logo ela poderia se tornar o único motivo para um cientista social que não fala alemão aprender a língua de Goethe" (Hennis, 2003, p. vi). O motivo para essa mudança de opinião foi a edição, feita por Knut Borchardt e sua colaboradora Cornelia Meyer-Stoll, dos escritos sobre a bolsa de valores, publicada entre os anos de 1999 e 2000. Hennis - como manifestou no jornal - viu aí uma "verdadeira sensação", porque finalmente se levava em conta, de forma apropriada, a obra da fase inicial de Weber e se fazia isso a partir de textos menos conhecidos sobre a bolsa de valores, um tema que permitia extrair muitas referências a questôes de grande atualidade sobre os mercados de capitais (cf. Hennis, 2000, p. L 52; 2003, pp. 96-102).

Mas a questão, plenamente justificada, é: qual é de fato a contribuição da MWG? Críticos e admiradores mencionam, sobretudo, as seguintes contribuições: a MWG põe à disposição os textos, as cartas e outras declarações de Max Weber em uma ordenação plausível. Além disso, desde a publicação 
das cartas, e especialmente das anotações para os cursos, o trabalho com os manuscritos de Max Weber, quase ilegíveis, foi reconhecido como um verdadeiro "trabalho de decifração" (Kaesler, 2010). Sem esse trabalho de base artesanal, as abreviaturas e palavras-chave de Max Weber não ficariam acessíveis nem mesmo aos mais experientes conhecedores do autor. Ao lado dessa atividade fundamental, menciona-se também a elucidação científica, em que contam o controle do texto, o comentário especializado, a contextualização e, como sempre, as introduções aos volumes. Com frequência, o trabalho de fôlego e detalhe que a edição exigiu é descrito com os adjetivos "perfeccionista", "meticuloso", "preciso" e "informativo". Idealmente, a edição oferece aos usuários um conhecimento novo sobre a gênese da obra, traz a público textos esquecidos ou desconhecidos e torna a obra completa compreensível, parte por parte. Com isso, a obra como um todo vai assumindo a forma de um tapete de urdidura cada vez mais densa (Lenger, 2011, p. 646).

A MWG é considerada uma edição clássica das ciências sociais e ciências da cultura de língua alemã ou, como formulou Keith Tribe, "a literary landmark of major significance for the social sciences" (Tribe, 2011, p. 9). A cada volume publicado, surge a oportunidade de discutir a obra de Weber, descobrir novas facetas ou ler com outros olhos textos já sacramentados. Isso ocorre na inter-relação entre desencantamento editorial e (re)encantamento a partir da recepção. $\mathrm{O}$ valor da MWG como a edição de um clássico está relacionado com a valorização do potencial intelectual, da perspicácia analítica do pensamento e da atualidade de Max Weber, pois a questão central para a vida de um clássico é se ele ainda tem algo a nos dizer para o esclarecimento de questôes e problemas de pesquisa atuais. Ao comentar os escritos de Weber sobre a Rússia, um pesquisador da Europa Oriental, Hildermeier, ficou admirado com o quanto as consideraçôes de Weber se relacionam com as pesquisas sobre a Rússia atual (cf. Hildermeier, 1992, p. 582). Gerhard Dilcher apresentou a relevância do autor para os historiadores do direito e Wilfried Nippel, para historiadores da Antiguidade (cf. MWG I/1, pp. 1-103; Dilcher, 2007a, pp. 105-156; Nippel, 2005, pp. 317-356). Por meio da edição dos escritos sobre a bolsa de valores e dos cursos de economia política, passou-se a render tributo ao Max Weber economista. O historiador social Friedrich Lenger, por sua vez, acredita que Weber não seja mais um impulsionador das discussões teóricas nas ciências sociais e na história alemãs desde o cultural turn (cf. Lenger, 2011, p. 646). A questão é se não deveria ser uma tarefa para o futuro libertar Weber das antigas estreitezas 
e apropriações pelas disciplinas e - como sugere Gangolf Hübinger - (re) descobri-lo mais enfaticamente como pensador histórico-universal (cf. Hübinger, 2011, pp. 75-86). Outra questão, não menos interessante, é em que medida - para além da Alemanha, da Europa e da recepção marcante de sua obra nos Estados Unidos e Japão - Max Weber pode assumir um papel importante na reflexão sobre as reviravoltas socioeconômicas e políticas contemporâneas, em vista do que se passa, por exemplo, no mundo árabe, na China e no Brasil.

\section{Resumo}

A obra completa de Max Weber - MWG: um retrato

$\mathrm{O}$ artigo reconstitui passo a passo o processo que levou à nova edição das obras de Max Weber. Expõe, assim, o desenvolvimento da concepção, estrutura, objetivos e critérios do trabalho editorial envolvido na elaboração da Max Weber Gesamtausgabe (MWG). Além disso, relata como se dá o processo de edição em si mesmo e explica quais são as formas de financiamento e como se estabeleceu equipe de pesquisadores responsáveis pelo projeto.

Palavras-chave: Max Weber; Max Weber Gesamtausgabe; Edição; Sociologia; História.

\section{Abstract}

The complete works of Max Weber - MWG: a portrait

The article provides a step-by-step reconstruction of the process that led to the new edition of the works of Max Weber. It describes the development of the concept, structure, objectives and criteria of the editorial work involved in elaborating the Max Weber Gesamtausgabe (MWG). In addition it provides an account of the editing process itself and explains how the project was founded and how the team of researchers involved was formed.

Keywords: Max Weber; Max Weber Gesamtausgabe; Editing; Sociology; History.

Texto recebido em 13/2/2012 e aprovado em 27/3/2012.

Edith Hanke é pesquisadora do escritório de redação da MWG na Academia de Ciências da Baviera, Alemanha. É também responsável pelo volume $\mathrm{I} / 22-4$ da MWG. E-mail do organizador do Dossiê Leopoldo Waizbort: <waizbort@usp.br>.
Errata: Na edição impressa, em vez de Simone Paulino, o nome correto da tradutora deste artigo é Sibele Paulino. 